\title{
Medieval Eurasian Communities by Comparison: Methods, Concepts, Insights*
}

\author{
Andre Gingrich
}

When an early 21st-century interdisciplinary research project comprises comparative investigations across three religions and their main realms of influence in medieval Eurasia as here, basic conceptual and epistemological approaches to history emerge. Despite their heterogeneous disciplinary backgrounds, most contributors to the present set of studies operate within the broad middle ground between universalism and particularism. A certain more or less explicit commitment to investigate comparative dimensions is invested from the outset, and thus combines with being open to scrutinizing and assessing potential similarities and parallels. At the same time, this combines with a solid respect for the specificities of particular historical processes in smaller and wider contexts. Writing "multiple histories" is a loose and flexible description for such a set of approaches. ${ }^{1}$

In view of current debates and buzzwords, it should be clarified that avenues toward elaborating multiple histories are by no means identical with actively participating in debates about "axial age" legacies, nor in sharing that paradigm. This does not deny that the concept "axial age" is as much debated and highly contested as it is pervasive. In one or the other version, as elaborated since the mid-2oth century by generalists ranging from Karl Jaspers (1949) in philosophy to S.N. Eisenstadt (1986) in sociology, ${ }^{2}$ this concept and the underlying sets of hypotheses have been fairly influential for the study of earlier periods in some of the same regions that this volume is engaging with. The basic "axial age" argument holds that between 800 and $200 \mathrm{BC}$, new ways of philosophical and religious thinking had appeared in written genres across major parts of Asia and Europe-providing a "breakthrough" to specific dynamics of state formation, and to new civilizational patterns with a focus on conceptualizing the relation between transcendental and mundane order in new ways, largely independently of each other yet sharing a basic emphasis upon

\footnotetext{
* The research for this article was funded by the Austrian Science Fund (FWF): F42 Visions of Community.

1 Gingrich, "Multiple Histories".

2 Jaspers, The Origin; Eisenstadt, ed., Origins and Diversity of Axial Age.

(C) ANDRE GINGRICH, 2016 | DOI 10.1163/9789004315693_022
}

This is an open access chapter distributed under the terms of the Creative Commons Attribution-

Noncommercial-NoDerivatives 3.o Unported (CC-BY-NC-ND 3.o) License. 
self-discipline and morality. ${ }^{3}$ It is true that more recent phases of debates and research ${ }^{4}$ based on this hypothesis have abandoned any dichotomy between "Orient and Occident" as introduced by Jaspers, and acknowledge more inclusive approaches and some priority for diversity without any inherent necessity for teleological hegemony. ${ }^{5}$ Still, by contrast to the somewhat more cautious approaches toward multiple history, "axial age" research by definition tends to lean more favourably towards universalist interpretations of its historical periods of interest - as is demonstrated by debates currently attracting archaeologists, historians, psychologists, anthropologists, and even biologists alike. ${ }^{6}$

Visions of Community, by contrast, investigates a smaller set of regions for more recent periods of history, with a more limited research agenda: this investigative process has set out to examine and comparatively assess processes of community formation between late antiquity and early modernity in selected contexts of Christianity, Islam, and Buddhism. In whatever ways these eras are understood and defined within regional and continental contexts, this will result in a historical focus on, roughly, the millennium between AD 500 and 1500. By definition then, explorations with such temporal and historical parameters will not focus on any results about the underlying reasons for and the main logic promoting the emergence of certain specified Eurasian religions but, rather, on insights into their enduring legacies, their dissemination, and their respective interpretations: What was the socio-economic impact on the ground once some of these scriptural world religions were established? What were their modes of actual operation at the levels of various local and supralocal communities? Within the current, new paradigmatic research contexts of the present, Visions of Community is one of the first research endeavours in this realm—clearly centred in its programme around the cooperation between historians, philologists, and socio-cultural anthropologists.

Similar only in that spatial regard to "axial age" debates, the present research endeavour maintains a selectively and loosely defined yet explicitly regional focus on the two continental realms of Europe and mainland Asia. This includes their mutual interplay as well as an appreciation of parallel yet not directly interrelated developments and, furthermore, recognizing Europe's growing intercontinental role since Mediterranean antiquity. Consequently, "Eurasia" is chosen as a descriptive and rather pragmatic term for this spatialtemporal focus. This choice comes along with a critical caveat about the term's

3 Árnason, "Axial Age", 47.

4 E.g. Graeber, Debt, Rüpke, Religion.

5 Armstrong, Great Transformation.

6 See, for instance, Baumard et al., "Increased Affluence". 
potential abuse, and, simultaneously, this choice does not necessarily entail any wider commitment to ongoing conceptualizations of Eurasia by other scholarly endeavours, although one might benefit from the other in the future. ${ }^{7}$

The following concluding remarks to this volume subscribe to an understanding of research as being always in flux, and usually as operating within bundles of partially interacting processes. ${ }^{8}$ In that sense, intermediate results from a collaborative research program with a duration of about a decade are perhaps just slightly more in flux than any other academic output. Still, these intermediate results would be of no benefit if readers' expectations and curiosity were to be constantly reoriented away from them towards the final results that may or may not be waiting somewhere in the future. In short, as partial as they may be, the present intermediate results deserve to be critically assessed in their own right. My concluding remarks will therefore aspire to emphasize some of those insights in the present volume that seem to be of a more enduring and wider relevance beyond the specific regional and historical contexts within which they were at first achieved. I will discuss this possible wider and enduring relevance primarily in dialogue with the comparative comments that accompany each of this volume's four main parts, thereby organizing these remarks into the corresponding Sections $2-5$. Before these, an initial methodological section will sum up some of the merits and potential of this kind of comparative inquiry.

\section{Cross-Cultural Historical Comparisons of Meanings: Methodological Toolkits}

Whenever historians, philologists, and socio-cultural anthropologists embark upon a joint comparative enterprise, early on in this process they are bound to discover that each of their respective disciplines has already been engaged in its own comparative practices for some time. While fairly self-evident within each field, these practices are acknowledged merely in passing by many

7 E.g. Hann, "Towards a Maximally Inclusive Concept of Eurasia".

8 The core version of the present text was written in December 2014 and January 2015 in Bali, Indonesia. Wherever the text refers to other chapters in the present volume, this is done on the basis of text drafts as they were available by that time. For their helpful suggestions and feedback on the March 2015 version of this chapter, I would like to thank the three co-editors of this volume as well as Brill's anonymous reviewers. In addition, I acknowledge having benefited from comments by the following colleagues: Regina Bendix (Göttingen); Philippe Buc (Vienna); Dipesh Chakrabarty (Chicago); David Gellner (Oxford); Barbara Götsch (Vienna); Chris Hann (Halle); Julene Knox (London); Charles Ramble (Paris/Oxford). Any remaining mistakes, however, would of course not be their responsibility but remain mine. 
outside. By necessity, historians (of various European and Asian societies) always compare their source materials and the social contexts to which they refer, or specific phenomena within these contexts, in terms of time lines-usually within smaller or larger regions, and within more limited time spans. Philologists (of various European and Asian cultures) also compare based on time lines, but in contrast to historians their sources comprise linguistic, written - and sometimes also spoken — material; they analyse and compare genres of textual production within and across specific linguistic traditions and their respective variants. Again by contrast, during ethnographic fieldwork in Asia or in Europe socio-cultural anthropologists constantly compare their hosts' interactions (including speech acts) with them, with others, and among themselves, and sometimes they compare the results of their findings with those from other cultural settings or with earlier reports about their host society.

When carrying out a joint comparative enterprise, each of these three fields is therefore prepared to move to a certain extent into the common ground where the three distinct disciplinary experiences and practices of comparison partially intersect and reinforce each other. In addition, each of them also brings their more exclusive and specialized comparative experience for potential cross-fertilization. The methodological procedures to be negotiated, tried out, and elaborated are "cross-cultural historical comparisons of meanings": Once you decide to work on medieval periods, your comparative exercises are bound to be "historically grounded" if not historical. While you cooperate in this, the type of available evidence requires the constant analysis of textual and other forms of "meaning". And as soon as you agree to carry this out across various regions of religious and linguistic diversity, cross-cultural continues to be the best available term to describe what you are actually doing. Crosscultural historical comparison of meaning is therefore understood here as a descriptive working term for the methodological toolkits, in the plural, employed by historians, philologists, socio-cultural anthropologists, and related disciplines collaborating in spatially and temporally grounded endeavours such as Visions of Community.

As an additional qualifier, the present endeavour is characterized by a preference for small numbers when it comes to operational size: small numbers of units to be compared, as well as of phenomena under scrutiny within and across these units. No privilege is therefore being assigned to the processing of big data but, instead, a clear priority is given to qualitative comparison on a small or medium scale. The advantage of working at this scale is that the appropriate methodological procedures yield much more detail and precision than is possible with the rough overview outcomes that usually result from big-data processing. 
What are the actual goals, purposes, and potential results of such a qualitative, tri-disciplinary comparative endeavour? Given an elementary research understanding of comparison as the analysis of similarities and parallels as well as of differences and contrasts, ${ }^{9}$ we may distinguish three markers of such goals, purposes, and potential results along a sliding scale of different scopes with specific challenges-i.e., between "a minimum challenge", through "a challenge of medium difficulty", to "a maximum challenge".

"A minimum challenge" to cross-cultural historical comparisons of meaning is to bring out the specificities in each case or process under scrutiny. This should be the basic aim and goal to be aspired to, which, if achieved, will be of great benefit, because the truly specific properties and features stand out more clearly when compared than if they had not been compared..$^{10}$ Even passionate followers of epistemological relativism or of empiricism should therefore be able to accommodate their convictions within this minimal challenge. A good example for such an endeavour is provided by Rutger Kramer's introduction to this volume's final section. On the other hand, if comparison in general and, likewise, if cross-cultural historical comparison of meanings in particular does not promise even a chance of yielding the minimal potential of highlighting the specific, then comparison is better avoided from the outset.

While busily identifying specificities, however, a researcher's comparative activity may once in a while - and perhaps more often than anticipateddeliver evidence of processes and cases that are not as unique as they at first sight appear, or that display certain dimensions that have parallels to other cases under scrutiny. This may then result in the insight that in some of its dimensions, an individual case or process represents just one item within a wider range. This I would call the "challenge of medium difficulty" among our three markers of possible goals and results. If successfully met, it may lead to the identification of certain dimensions in specific cases or processes as examples within a more or less wide range of diversity as a class or set of variants. ${ }^{11}$ It is precisely this range, set, or class that may then become the new focus of theorizing and of conceptualization. In fact, the mere establishing of inventories of diversity would fall short of actually tackling the challenge of medium difficulty, and would amount to little more than "collecting butterflies" - as Edmund Leach ${ }^{12}$ once disapprovingly referred to such documentary

9 Gingrich, "Comparative Methods"; Palmberger and Gingrich, "Qualitative Comparative Practices".

10 Pohl, "Comparing Communities"; Rosenwein, "An Historian in the Amazon".

11 See Grossberg, "Identity and Cultural Studies".

12 Leach, Rethinking Anthropology. 
endeavours of limited intellectual relevance. Unless the range (or set, or class) itself becomes the focus of conceptualization (which would include a recognition of its internal varieties and their rationales), the mere celebration of diversity falls back into emphasizing many specificities. For some, this may be the golden road for their hidden agenda, namely, towards elevating the specificity of their choice and its allegedly unique role within humanity at large.

Once a range (or set, or class) of diverse historical phenomena has been regionally or cross-culturally proposed, discussed, conceptualized, and sufficiently theorized, one may move on to other related or unrelated phenomena. Alternatively, in a few of these instances of more or less wide ranges of diversity, clusters may eventually become apparent. Wherever such clusters of sets and examples are discernible, and in the event that several of them contrast with each other in meaningful ways, this would then allow the elaboration of typologies. Formulating such comparative typologies (which may or may not be related to Max Weber's "ideal types", see Pohl's introduction to this volume) is what I would call the "maximum challenge" in cross-cultural historical comparison of meanings. Scholarly representatives of some epistemological orientations will be less enthusiastic than others about addressing this challenge at all. Still, an "abductive" approach ${ }^{13}$ rather than either a strictly deductive or a narrow inductive line of reasoning might accommodate at least a fair number of the sceptics.

So some basic methodological agreement on comparative goals and aims is essential, despite and because of epistemological pluralism: be that in the minimalist sense only, or beyond that by at least trying to also integrate medium and maximum goal dimensions. On such a basis, cross-cultural historical comparisons of meanings, just like any other comparative procedure, require some clarity about the "empirical features" of comparison as well as about the "cross-cutting criteria" by which these features will be comparatively assessed. In one crucial sense, the question of whether specific features are empirically available is based on the evidence and its potential. If the available sources, however narrowly or loosely they are identified and interpreted, do not yield any evidence in one set of cases and processes then there is nothing available to be compared. Yet often there is, and within such a given range of options and choices about available and potential evidence, path dependency and theory then intervene. In the other sets of cases under scrutiny, if an abundance of relevant source materials is available in one case of sets and processes, it may still not be useful to subject them to comparison if they do not correspond sufficiently or do not correspond at all. Alternatively, there may be an 
abundance of source materials available in several sets, yet these materials then may have no apparent relevance for the key research question. The empirical features of comparison in this volume, and the cross-cutting criteria by which they were examined, thus had to fulfil precisely these two sets of conditions: first, substantial relevance for the central research question(s) about "visions of community", and second, a minimal source-based occurrence of evidence across all (or, at least: across most) European and Asian cases under scrutiny in order to make comparison not only meaningful but, even more importantly, possible.

Since the key research question asks about the integrating effects of visions of community, a first obvious field of comparing relevant evidence relates to public references about and by communities. "Addressing communities" in terminology, tropes, or textual genres, and analysing contexts, structures, and actors in these processes of addressing communities was thereby chosen as the first of four subfields of investigation. The other three subfields were then singled out for the purpose of scrutinizing specific social arenas through which processes of community formation would take place. The second and the fourth subfields are "urban settings" and "spiritual communities" (i.e. monasteries and other comparable "enclaves of learning") that to an extent allow analyses from "below" and from the "inside" while also relating these to wider interactions in the respective regions and the outside world at large. The third subfield is more explicitly oriented toward the formation, articulation, and representation of elites and toward their "top-down" perspectives, taking "genealogies" as a strategic avenue for analyses focused on this purpose. In theory, other choices of subfields might have been possible, but together with only a few alternatives, the present choice best fulfilled both methodological prerequisites as previously outlined and answers theoretically inspired key questions by means of analytical assessment of evidence through processes of cross-cultural historical comparison of meanings.

\section{Diverse and Similar Ways of Addressing "Community"}

A recent introduction to the topic of the "Visions of Community" project ${ }^{14}$ has already explained that for comparative purposes of Eurasian medieval history, the term "community" is best understood as a low-threshold research concept referring to group identity formation processes in context. Such an orientation

14 Gingrich and Lutter, "Visions of Community: An Introduction"; see also Lutter,

"Comparative Approaches". 
simultaneously distances itself critically from two alternative approaches which are not useful or productive for our present purposes: first, an "exclusively native" approach might prefer to accept evidence for addressing community only when and where the term "community" itself or a one-to-one correspondence in other languages occurs-thereby ignoring all other possible processes of group identity formation that did not find their way into this narrow crystallization of terminology chosen by specific authors in their chosen periods. Second, an "exclusively modernist" approach might prefer to search specifically for those indications of community that seem to speak to the quasi-evolutionist theories ${ }^{15}$ according to which community is seen as more or less synonymous with the pre-modern. From the outset this approach thus introduces a theoretical paradigm that by definition cannot be shared by many experts of medieval Eurasian studies, namely, society as a more recent and more modern sequence to the allegedly more archaic, pre-modern formations of community.

Current approaches to addressing medieval communities, such as the majority of those represented in this volume, are thus not exclusively nativist and are non-modernist at the same time. Their primary reference and scriptural evidence are what might qualify as key items in public discourse, such as language and text productions designed for wider circles of readers and audiences with the explicit intention to leave a mark, to convince, and to remain relevant over time. Socio-cultural and public contexts as well as authors' agency within these contexts thus emerge as key dimensions of analysis, as Heiss and Hovden (this volume) appropriately observe in their comparative reflections on this subfield. Still, they do not deny the continuing salient relevance of source criticism, etymological assessment, or of semantic and literary criticism in general as essential prerequisites. The fact that these tropes and themes in medieval public discourses on community, just as on many other subjects, were framed within religious paradigms is self-evident: any a priori separation between religious and other public spheres of life in those circles and strata of medieval Eurasia that were able to read would have been exceptional, if such separation existed at all. The fact that most texts and arguments as analysed by Heydemann, Lohlker, Hovden, and Heiss are embedded within rationales that either seek to elaborate and confirm religious norms (Heydemann, this volume), or at least to explore the ranges of potential agency without openly contradicting them (Lohlker, this volume), is not an unexpected insight. Although corresponding analyses from Tibeto-Buddhist realms

15 See Tönnies, Community and Society, but also Parsons, Action Theory and the Human Condition. 
are unfortunately still lacking in this subfield, it is highly unlikely they would deviate in this basic regard. What is new in the comparative exercise on addressing community here is the diversity of forms; yet once the analysis moves on to a level of modest abstraction, a fair amount of similarity about the basic social forms of community is actually addressed beneath and beyond normative religious paradigms. A certain search for social realism within their sources of course informed the researchers' choices from the outset. Yet conversely one may also argue that a healthy amount of social realism precisely facilitated the enduring relevance of these sources over time.

Rüdiger Lohlker's distinction between community-centred and rulercentred visions of community in the Arab-speaking early centuries of Islam is a good case in point. Lohlker starts with a clear distinction between certain terms' modern and contemporary use and abuse, and their different meaning in early and medieval Islamic history. By elaborating some of his earlier contributions to this field, the author demonstrates how other more practical terms came into use alongside a normative theological one in early and medieval Islam, and these were used differently according to the social interests of various stratified players. Historical anthropologists would hope that such splendid insights from Arabists' analyses might also find some more regionalized grounding within their respective time horizons, that is, to specify whether these distinctions were similarly relevant for regions and developments as distant as, say, Andalusia and Oman. Yet notwithstanding such open questions for future research, an innovative and important breakthrough has been achieved that simultaneously sets an example for similar investigations in other linguistic and discursive traditions.

In a way, Gerda Heydemann follows similar pathways while arriving at different results for the three centuries during which Christianity found its way from Western Asia to the centres of Mediterranean Europe (3rd-6th century). Her study of diverse interpretations of Deut. 31:21 by Christian exegetes first of all reveals a plethora of flexible terms for the "community of God" and their usages according to context and purpose, including their reference to rivals and outsiders. This basically highlights the changing meanings of populus and gentes, which could serve inclusive as well as exclusive arguments. Heydemann, as well as Heiss and Hovden in their response to her-which itself is primarily based on evidence from the Arab peninsula in general and from South West Arabia in particular-raise the issue of ethnic diversity and of interethnic relations in their discussions. By precisely historicizing their contextual relevance and purpose, Heydemann as well as Hovden and Heiss identify the various purposes of usage of these terms, while simultaneously confirming their overall secondary relevance. None of these contributions argues that the topic of 
ethnic diversity was of primary relevance for the authors and the texts under scrutiny, let alone that the topic was addressed in any manner in isolation from other, usually more important themes.

Yet having said that, it nevertheless remains worth mentioning that ethnic diversity and interethnic relations were indeed an explicitly addressed sociocultural topic and a more or less secondary feature in many early medieval authors' references to processes of community formation. This may not be a sensational new insight for medieval historians or for historical anthropologists - after all, why should authors and their interested public in those centuries not have been able to address linguistic and cultural diversity when it came to their attention? Yet for those historians of modernity, and for those anthropologists of the contemporary who for a long time have repeated their convictions about ethnicity allegedly being an invention of European modernity (or, for that matter, of European colonialism), this may actually come as the most significant eye-opener in the entire volume before them. "Ethnicity", not as an academic and analytical concept but as a social and cultural interrelation, did not require the curious gaze of modern Europeans to come into being. It was certainly redefined and thereby newly installed as a concept for specific purposes by early modern and colonial European interests-but that does not preclude its prior existence in those scholarly and everyday forms of knowledge characterizing the different contexts of antique and medieval Eurasia.

In addition, the debate between Heydemann, Heiss, and Hovden is indicative of a certain structural relativity in the relationship between interethnic formations and the smaller or larger units with which they might intertwine. In Western Asia, tribe-like or tribal units were usually seen as being of somewhat smaller size and positioned either within or at the periphery of much larger and more heterogeneous units that could be understood as ethnic or regional majorities. If we also include smaller ethnic (i.e. linguistic and/or religious) minorities, a tripartite pattern emerges that became widespread across Asia in general, while in Western Asia in particular it could build upon old Semitic traditions ranging from Gilgamesh's epic narrative ${ }^{16}$ to the twelve tribes of Israel in the Old Testament, in which Israel is represented as the (larger) ethnic group composed of a definite number of (smaller) tribes. Muslims continued to tolerate and to promote these distinctions of structural relativity while including, embracing, and integrating them into Islam's concepts of "communities of believers". By and large, these historical Asian and Western Asian relations therefore situate tribal or quasi-tribal entities as medium-sized units that are smaller than those ethnic majorities of which

16 Dostal, "Konstanz von Kulturformen". 
they are a part and which may also include non-tribal sections; simultaneously, the same tribal or quasi-tribal entities are larger than the ethnic (i.e. linguistic and/or religious) minorities that may or may not coexist within the overall constellation. In early exegetic Christian discourses this relative and loose conceptual structural relation between "larger" ethnic units and "smaller" quasitribal subunits (which might again include ethnic minorities), while not a stable given, was obviously even more frequently rhetorically and ideologically shifted and turned around according to contexts and to the authors' intentions.

Against the backgrounds of those Middle Eastern legacies, Johann Heiss and Eirik Hovden suggest also considering the tensions and conflicts in medieval South West Arabia of the gth and 1oth centuries AD from an interethnic hierarchical perspective. Although both sides in those conflicts followed certain versions of Islam, and both of them spoke particular versions of Arabic, available sources make it quite clear that regional socio-cultural differences-including vernacular language and ancestral understanding — mattered more than broad commonalities of language and religion. Interpreting the (North West Arabian) "Alids" gradual establishment in South West Arabia from the 1oth century as a conflict-ridden process with interethnic dimensions contributes not only to our understanding of the formation of tribal and religious communities in medieval Yemen; in addition, it makes those regional Yemeni processes more readily comparable to developments elsewhere in wider regions such as North Africa and the Greater Middle East, wherever parts of the newly established local elites were for some time of North Arabian background. Furthermore, these processes in medieval Western Asia to some extent have their interethnic counterparts in certain corners of medieval Europe as well-Norman and Plantagenet elite formation in England after the battle of Hastings being the best known. Interethnic elite formation is thus an important by-product of these comparative reflections on ethnicity in medieval Eurasia.

If addressing communities as embedded within "hierarchical social strata" is thus one enduring outcome of this volume's first part, and communities as "secondary interethnic affiliations" across various parts of Eurasia is a second one, then the tribal topic as addressed by Heiss and Hovden represents a third noteworthy result of these comparative interdisciplinary efforts. In my understanding, their concise outline of the usage of different terms in the Quran (with the Hijazi and Western Arabian linguistic context of original emergence in the 7 th century $\mathrm{AD}$ ), and primarily as used by two different authors (with their respective backgrounds in central Yemen, and in Yathrib/Madina) from the 1oth century for tribal groups of the Yemeni highlands, is again exemplary in its careful and detailed assessment and conclusion. As a result, Heiss and 
Hovden are able to highlight the different political intentions and conflictdriven agency involved in both main texts under scrutiny. Consequently, they insist on the necessity of identifying not only context, but also agency-and specifically authors' agency - in the version of cross-cultural comparison of meanings that is implemented here. To this set of orientation markers-that is, contexts and agency - I would like to add structures, and structural relations. This leads to the proposition of a "methodological triangle of key markers of orientation" within which the processes of cross-cultural comparisons of meanings might profitably oscillate and unfold, in other words, that triangle being marked by contexts, agency, and structural relations.

In the particular case analysed by Heiss and Hovden, semantic and etymological analysis provides the relevant "structural" indicators that confirm existing ethnographic insights. 'Ashira - the North Arabian term used most frequently by the 'Alid author for tribe - goes back to the Arabic word, inter alia, for the number ten, and here paraphrases a background of common ancestry lasting about ten generations. The North Arabian term thus emphasizes time, and long sequences of generations. By contrast, the South Arabian Qabila, used regularly by the Yemeni author for tribal groups, in etymological terms refers back to the Arabic word for, inter alia, the spatial position of being in front of something or somebody. Here it paraphrases a background of coresidence among others, "in front of" whom one speaks and acts. The South West Arabian (and, likewise, the more frequently used Quranic) term thus emphasizes space, location, and co-residence rather than time, generations, and descent. Ethnographic analyses throughout the past three decades have been pointing out that in their basic dimensions the tribal formations of South West Arabia were essentially territorial by configuration while genealogies were less important for the non-elite tribal people but primarily relevant only for the tribal and non-tribal elites. ${ }^{17}$ By contrast, ethnographic analyses from Northern Arabia demonstrate the much more pervasive role of long chains of descent in various social status groups among the elites, yet partly also beyond them. ${ }^{18}$

To sum up, the sources examined by Heiss and Hovden on various usages and meanings of tribe in 1oth-century Arabia (and before that) primarily indicate different "contexts" and opposing "agency". Yet as a third marker of orientation, they also seem to imply different "structural relations", here those of personal and group affiliation to tribal status and the inherent orientation of that status in different parts of Arabia, namely, of a more territorial structural

17 See e.g. Gingrich, "Multiple Histories" and the references indicated there.

18 See e.g. Shryock, Nationalism; Musil, Manners and Customs. 
orientation in the southwest and of a more genealogical structural orientation of tribal groups in the north of the Arab peninsula.

\section{Urban Medieval Settings and the Relevant Priorities of Classification}

Comparing medieval urban settings across Eurasia to an extent is a matter of scale, as, unavoidably, are all comparisons, within certain limits. The smaller the scale, the greater the attention to detail, and, by consequence, the more likely it is that the analysis of specificities will predominate over the identification of similarities with other comparable cases. This is the methodological side to a somewhat problematic coin-in other words, why the present explorations into medieval and early modern urban settings of Central Europe, the Dalmatian Coast, and South West Arabia yield three studies in regional diversities rather than, at this point, any comparative analysis across continents. The case is further aggravated by the absence of corresponding investigations from the Tibeto-Buddhist realms, for which many experts continue to claim that the term "urban" is not even applicable in the medieval and early modern periods.

The other side of the same coin is theoretical in nature, as indicated by Walter Pohl in his introduction as well as by Gruber, Heiss, and Hovden in their joint comparative reflections on the urban subfield (this volume). Throughout the 2oth century, questions of urban constellations and their roles in Eurasian history were loaded and in fact overburdened with theoretical claims and interests. This is particularly true in relation to the oeuvre of German legal and economic historian and sociologist Max Weber in the early zoth century, which in this regard still continued to have its negative resonance with Karl Jaspers' early version of the axial age hypothesis by the mid-2oth century. One of the key propositions put forward and popularized by Weber-albeit suggested by several before him, and further elaborated by many of his followers-concerned cities' special relevance for Europe's unique pathway(s) into modernity. Weber and many Weberians argued that legal freedom for certain cities and citizens of late medieval and early modern Europe became the decisive precondition which opened up the way for the unprecedented growth of capital, the emergence of the urban bourgeoisie, and Europe's subsequent leadership in mercantile, colonial, and industrial hegemonies. ${ }^{19}$

19 Bruhns/Nippel, eds., Max Weber und die Stadt; Weber, Wirtschaft und Gesellschaft. 
Apart from the many productive consequences for research which these theses and their impact indeed have had, which are not being denied here per $s e$, they have also implied a downside for medieval historians of Eurasian cities. Most importantly, the Weberian theses increased the modernist pressure upon them: their studies' relevance was often treated in a reductionist and instrumental manner as if they were only meaningful as long as they delivered building blocks in support of these theses, that is, pre-modern outlines of the emerging presence of the urban liberties that advanced European cities, and how their absence left Asian cities lagging behind. It is understandable then that for some time a set of theses was transformed into something close to a dogma and ended up inadvertently suffocating good new interdisciplinary research by historians, philologists, and anthropologists in the relevant subfield of comparative urban investigations across medieval Eurasia. In consequence, precisely because such large-scale comparisons could hardly avoid the suffocating effects of the Weberian theses for medieval urban studies in Eurasia, a healthy retreat set in within this particular subfield and by means of such tri-disciplinary cooperation. Instead, new source materials were identified in micro-regions, new methods for their analysis were elaborated and tried out, and on that basis small-scale regional comparison was reinvigorated.

In sum, there are particular methodological and theoretical reasons why at this point the specific subfield in which historians, philologists, and anthropologists study medieval and early modern cities in Eurasia is yielding elements of well-developed regional comparison, which, however, are so far only loosely interconnected with each other at conceptual and intercontinental levels. To my mind, this also raises the question of whether these three disciplines engaged in the urban subfield can afford to continue this conceptual paralysis caused by the Weberian theses, or whether it is high time to profit from neighbouring disciplines that have been less haunted by an inappropriate priority given to a modernist paradigm. After all, Weber elaborated his theses before and after World War I - at a time when European colonialism had peaked, when (Western) European hegemony had reached a global scale, and while for a few decades it appeared as if that constellation could last forever. In such a context, a thesis about the origins of that allegedly enduring role of Europe in world history could potentially have been fascinating to many.

However, merely a hundred years later we are already aware that European hegemony in the world has not even outlived that century. Moreover, since the studies of Joseph Needham and his network of collaborators ${ }^{20}$ we have come to realize that the levels of technological and intellectual complexity and 
sophistication achieved in China (and elsewhere in Asia) were rarely actually "lagging behind Europe" before the 15th and even the 16th centuries. In short, European hegemony in many ways has gone today, and its overall duration in world history was much shorter than Weber and his contemporaries would have expected. As a result, the question of European urban specificities turns out to have less world historical relevance than was assumed $5^{0}$ or 90 years ago. ${ }^{21}$ Weber's theses on the absence or presence of urban legal freedom have not become irrelevant, but they are far less important than previously assumed, and they need not set the priorities of medieval urban studies in Eurasia.

The world's largest and most sophisticated city between the 9 th and the 12th centuries was Angkor, in what today is Cambodia. During its peak era Angkor covered an area about the size of today's Berlin, while hosting about one million inhabitants. In addition to its size and complexity, it is also highly probable that Angkor offered its residents one of the best living standards available anywhere on the globe at the time. One of the leading experts, Australian archaeologist Roland Fletcher, has systematized these and other key indicators to conceptualize "low density/larger size" (or: dispersed) types of medieval garden cities with Angkor as one key example, and to contrast them with "high density/smaller size" cities with correspondingly lower levels of agriculture and garden cultivation. ${ }^{22}$ In principle these two forms can be conceptualized as the poles or extremes at the two ends of a scale, with a variety of intermediate forms between them. Yet empirically and historically, the polar forms were fairly widespread and come close to what was addressed in the second section of this chapter as types. Both of these types outlined by Fletcher shared what by definition characterized urban settlements, at least in medieval Eurasia: a relative demographic concentration and agglomeration, a nodal position with wider networks of communication and transportation of all kinds, a relatively higher occurrence — if not a "critical mass" — of specialized intellectual skills related to administration, communication, and religion, and thereby including, among other things such specialized crafts as the arts of writing and reading. The first dispersed or garden type (type 1 for present purposes) according to Fletcher included features of the Roman oppida, while in Asia, type 1 occurred in the dry zones of northern Sri Lanka before the 13th century, and reached its maximum form in Angkor after the 11th century. Because of its higher integration of horticulture and agriculture, this type 1 involved two additional features: first, it displayed a gradual rather than any abrupt transition toward the wider rural environment, and, second, for the same reasons

21 Chakrabarty, Provincializing Europe.

22 Fletcher, Limits of Settlement Growth; Fletcher, "Low-Density, Agrarian-Based Urbanism". 
this type was fairly exposed to seasonal instabilities. This is why it declined somewhat more easily if such environmental crises exceeded certain limits. Many archaeologists of Asia such as Fletcher are convinced that the dispersed, low density/larger size garden type 1 of urban development was more widespread in medieval history than had been understood until recently.

Fortunately enough for historians, philologists, and anthropologists of medieval Eurasia, archaeologists with the same regional and temporal expertise have therefore elaborated a broad intercontinental comparative typology that permits debates and assessments in this field without necessarily engaging with Weber's theses. As Gruber, Heiss and Hovden (this volume) already propose, this archaeological typology does in fact operate with empirical criteria such as size and demographic density. This, then, offers an opportunity to conceptually experiment with the "maximum challenge" addressed in this paper's first section, i.e. the identification and trying out of certain types. If Fletcher's typology is therefore applied for present purposes as I suggest, then two new hypotheses would emerge from such an exercise.

First, a Tibetan hypothesis on horticultural urban settings: it would in fact seem worthwhile explore with some patience and in some detail whether any of the larger oases on the Tibetan plateau in medieval times might perhaps figure as dispersed settlements which in their wider regional contexts could emerge as coming close to peripheral subversions, or peripheral proto-versions, of Fletcher's "dispersed" type 1 . While it was often argued that there were "no cities in medieval Tibet", this argument was consistently formulated on the assumption of type 2 models, namely, of a high-density/smaller-size pattern, which indeed would not apply to medieval Tibet. The case might look different if type 1 were used with an eye for potential sources: "Part of the problem is sources, but an even bigger problem may be the fact that no one has really been interested in looking for those sources". ${ }^{23}$ For such an endeavour, we have to consider that population density and size are relative and relational criteria to be assessed in their respective contexts. What may look like a large group of dispersed villages in contemporary Yemen or Bohemia might in fact represent a proto-version of type 1 in medieval Tibet, where such a larger group of dispersed villages would have to be situated in one of the plateau's few oases while being surrounded by sparsely populated, vast areas of arid nomadic lands. Perhaps, by contrast, the oases would once in a while also attract a market, a garrison, a monastery, or all of these.

Secondly, a South West Arabian hypothesis on the mixed occurrence of horticultural (type 1) and mural (type 2) medieval urban settings: As for the three cases of

23 Charles Ramble, personal communication, March 19, 2015. 
Sanaa, Zabid, and Sa'da, which Heiss and Hovden introduce into their joint analysis with Elisabeth Gruber (this volume), these three urban medieval Yemeni examples are certainly fairly representative South West Arabian versions of the mural type 2. Yet simultaneously, none of them represents the kind of horticultural type 1 , or the dispersed oasis garden settlement that simultaneously existed elsewhere in South West Arabia too. The dispersed oasis settlement of Najran, or some of the major settlements in the Wadi Hadramawt, would be relevant cases in point. On the other hand, during certain phases of history the capital, Sanaa, could be reconsidered; in fact it might have represented a mixed form situated somewhat closer to type 2 than to type 1 . These examples indicate that South West Arabia in this regard differed quite markedly from the Tibetan plateau as much as from the Central European and Dalmatian cases throughout long periods of the millennium under scrutiny:if Fletcher's distinction is applied to a larger sample, South West Arabia hosted both basic types of urban setting.

In short, once the large but basic scales of Fletcher's typology are used for the three regional case clusters discussed as urban settings in this volume, then it turns out that at first sight they all seem to belong to type 2. So notwithstanding their important socio-cultural and architectural differences, a certain large-scale perspective such as Fletcher's typology reveals that Dalmatia's early modern island cities, Central Europe's border towns, and some of the Yemen's most important urban-mural settlements have more in common than is apparent at first sight. Their basic demographic and subsistence patterns all feature much higher population densities within sharply confined boundaries, along with a lower amount of horticultural and agricultural subsistence areas inside these urban settlements, and a more clearly marked division of labour between type 2 cities and their immediate environments. According to Fletcher, this type is less susceptible to in situ decline or abandonment and subsequent reinstallation elsewhere, and it displays a more inflexible bipolar tendency toward either longevity or disappearance.

If these lines of reasoning are pursued somewhat further, the present research subfield of envisioning communities among urban settings across medieval Eurasia might come to the point where fascinating insights can be positioned within wider forms of reference and typology. With his distinctions of various forms of othering in the community lives of the Dalmatian towns he investigates, Oliver Schmitt (this volume) already provides a lucid line of orientation which could lead to such insights in a given case of comparative analysis. Gruber provides inspiring elements of network analysis and of differing forms of urban specialization in regional contexts that also have great potential for further elaborating and refining criteria and tools for comparisons of type 2 settlements. 
A further continuation of the kind of reasoning proposed here would ultimately allow the question of comparative subtypes within and across types 1 and 2 to be addressed, in addition to intermediate forms between 1 and 2 in Asia (such as, perhaps, Sanaa) as well as in Europe (such as, perhaps, in Rome after late antiquity as suggested by Pohl [personal communication]). This might then open up a reconsideration of some enduring insights by a 2othcentury master of historical and economic anthropology, Karl Polanyi. ${ }^{24}$ After all, Polanyi's concept of "ports of trade", for instance, designated a very specific but widespread subset of urban conglomerations. This subset rarely found its way into the Weberian legacies of reasoning, and neither does it yet have a place in Fletcher's typology: from my perspective, however, ports of trade as a possible type 3 would have to be considered as cross-cutting both types 1 and 2-coexisting with each of them in dependent ways and intermittent cycles of existence, but also existing without either of these two types in cases of interaction with a suitably structured rural or insular hinterland. The integration of "ports of trade" into a refined and elaborated form of Fletcher's typology will be indispensable for understanding and analysing some of Eurasia's medieval communities' key contact zones with their outside worlds: perhaps, after all, several of Dalmatia's proud early modern port cities can best be comparatively assessed precisely from such a perspective.

\section{Scrutinizing Medieval Genealogies}

The genealogical subfield of the present inquiry can build on a fairly straightforward and explicit comparative cross-cultural basis and, in that sense, it faces less challenging tasks than the subfields discussed so far. In its empirical dimensions, this comparative cross-cultural basis is provided by evidence from all over Eurasia, that is, by all regional fields under scrutiny here. In their methodological and conceptual dimensions these grounds have been exceptionally well prepared by more than a century of anthropological kinship analyses and their cumulative and revised results.

Genealogies are records of the passing on of expertise, offices, and/or property from one past generational representative to a successor through alleged or metaphorical lines of streamlined descent. Quite elaborate versions of such records are known in predominantly or exclusively verbal form from West African history, where they were transmitted by performance experts, for example from the Griot stratum. Yet across medieval Eurasia such verbally or 
poetically memorized genealogies seem to have been exceptions to the rulewhich was the transmittance of genealogical records either through written text alone or through combinations of text and imagery.

By definition, succession in office, in expertise, or in property per se is not identical with descent, although both concepts connect the present with the past by informing one through the other. Claims of streamlined descent may, but need not, serve as an implicit or explicit grammar for the construction of genealogical records. In fact, at times, representing records of succession as being connected through direct descent may not even have appeared necessary for the authors, as Pohl demonstrates (this volume) for Merovingian history or as is known for generations of successive Zaydi Imams in the Yemen between the 1oth and the 15th centuries $\mathrm{AD}$ (who were only related to each other indirectly by common belonging to the house of the Prophet Muhammad). Cases such as these indicate that succession in office was more often merité rather than herité, with the meritocratic principle rarely being implemented without violence and conflict. In turn, meritocratic instances testify to the non-identity between genealogies and records of descent.

The distinction between descent and genealogy is illustrated even more explicitly through the depiction of representatives of theological wisdom and religious expertise in medieval Europe (Opitz, this volume) and Tibet (Kellner, this volume). In fact, these genealogies of religious wisdom explicitly use notions of descent merely as a peripheral metaphor, while simultaneously, and more importantly, this peripheral metaphor is substituted by something much more valuable in the eyes of contemporary artists, spectators, and readers: the transmission of religious wisdom is passed on across generations-from teacher to disciple in Central European cases, and from one rebirth or reincarnation to the next in the Tibetan case, as impressively analysed in Birgit Kellner's pioneering contribution. Both these modalities thereby, in a way, celebrate the inferiority of descent and the superiority of succession principles by means of higher values and ideas. Kellner observes that the resulting genealogies were no "visions of the archaic" but contemporary attempts at ordering the social world. Still, in almost all extant cases the lines of succession are composed exclusively of male names, and in that sense they do echo and resonate with pre-existing notions of patri-lineage among their readers and spectators despite their explicit hierarchical distance to descent principles.

It is worth mentioning at this point that even if the successive lines of generational representatives were composed of females alone, one basic feature of genealogies would not be erased: in principle, the political and religious quest to author and establish written genealogies evokes the unavoidable necessity of representing the relevant names as if they emanated from a 
"unilineal descent order or lineage", be it patrilineal or-as among certain historical kingdoms of southern Africa, for example - more rarely, matrilineal. By its unavoidable proposition of a step-wise and thereby linear sequence, the genre of written transmission across many generations therefore evokes and promotes per se the representation of unilineality. In turn, unilineality necessitates the streamlining, the erasure from written records of those members of previous generations who have no relevance for succession. "Structural amnesia" is therefore an indispensable technique and ingredient within any form of genealogical representation. In addition, methods such as "telescoping" and "merging" have been identified throughout decades of kinship analysesmethods by which unilineal genealogical chains can be constructed, invented, or simplified for many of those instances where other ethnographic or historical evidence points to the contrary. ${ }^{25}$

We have thus left the basic realm of non-identity between genealogy and descent and moved on to those more specific genres in which the integration of descent into genealogical representation is seen as desirable, necessary, and legitimate. For these cases—often of a dynastic kind — the important point has to be reiterated that genealogical records not only reflect and illustrate unilineal (mostly patrilineal) reasoning among certain elites: simultaneously, they serve to inform and organize this type of descent reasoning among the elitesthat is, by contrast to the majority population. If more than, say, seven to twelve predecessor names have to be memorized then this either requires experts in verbal mnemo-techniques or visualized, mostly written records. Simultaneously, even written records of more than twelve predecessors may easily become too complicated if they are not streamlined and manipulated as outlined, on unilineal principles and according to aspects of authority, power, and legitimacy.

It was stated from the outset of this section that the analyses of medieval genealogies in Eurasia primarily concern various elite strata. We now can add that, in particular, these genealogical representations dealt with their inner organization as well as with their public display. To an extent, this also concerned their social distinctions vis-à-vis each other and, more importantly, against the medium and lower strata and status groups. Two more general aspects of kinship and of literacy underline this point. Literacy, on the one hand, can only be inferred from more recent indicators: yet if, for instance, the literacy rate in northern Yemen shortly after the collapse of the Imamate in the 1970 s was estimated to be less than 25 per cent of the population then it is highly probable that a millennium earlier it was not higher but rather lower 
than that on the average, notwithstanding phases of rising and falling occurrence. So, in addition to the fact that written genealogical records for members of the middle and lower classes are rare, then there are good reasons to assume that such records not only are not known today but that neither did they exist in medieval times, because they could not be used. On the other hand, as far as kinship is concerned at large, genealogical memories and descent reckoning are merely one of several strategic elements in any kinship system-the other key elements being marriage options and practices, inheritance rules, and terminology. From a comparative ethnographic perspective, the one-sided and biased elevation of genealogical records and descent order above all other key elements in a kinship system is usually a distinctive characteristic feature of elites' desire to mark their special status, while the same being fairly atypical in most other strata of society.

Kinship and family in the middle and lower strata and status groups of urban and rural contexts often followed differing versions of kinship forms, including much shorter chains of descent in unilineal cases or, alternatively, one or the other of the non-unilineal forms identified by anthropological analyses such as bilinear and bilateral forms. In large parts of Central Asia including the Tibetan-speaking areas, for instance, ethnographic evidence demonstrates the widespread occurrence of bilateral elements in local kinship systems by which the matrilateral side contributes the "flesh" while the patrilateral side provides the "bone" to a person's identity. In turn, these strong bilateral elements in local kinship systems are in marked contrast to the more explicit patri-lineage metaphorical representations among the elites. In addition, the earlier argument about the basic non-identity between descent and genealogies has to be supplemented by a similar point about descent and inheritance. As most cases of Islamic law demonstrate, the official reckoning of descent may be unilinear while inheritance rules basically follow bilinear principles.

It therefore to a certain extent makes sense to argue, as Pohl and Daniel Mahoney do (this volume), that genealogical reasoning was more relevant in medieval Arabia than it was in medieval Europe. Yet, as we have seen, this had its clear limits even inside Arabia-where it was somewhat more relevant in Northern Arabia than in the south-west, and in both of these regions it was more relevant for the elites than for the broad middle and lower strata. The elites' special interests did not coincide with the living conditions of the common people regarding family organization, property rights, or the status of women. The elites certainly were influential in their respective arenas, and they evoked mimesis as well as support-otherwise they would not have remained elites for long. Their rhetorical claims, including their genealogical 
statements, were primarily self-referential but simultaneously they included claims about the rest of those societies in which they were the leading forces. Still, discursive influence is one important element in elite organization, and elite distinction is another.

\section{Spiritual Communities and Their Enclaves of Learning}

My final section concerns the largest subfield in this volume, namely, spiritual communities and the related "enclaves of learning" which many of these spiritual communities across medieval Eurasia inhabited. Quite obviously, this subfield has gone through longer and even more productive discussions and comparative reflections than the other subfields under scrutiny. This section has the most contributions in this volume-including an introductory overview of its own and two comments - and it also is by far the most intensely discussed. After a long period of tilling and sowing we may thus benefit from a productive intellectual harvest. In turn, this allows me to confine my concluding remarks to three main points: conceptualization, selected insights, and a few consequences.

First, on conceptualization: a number of contributors to this section (Kramer, Hovden, Hugon, Vanderputten, Lyon) explicitly refer to the underlying concept of "enclaves of learning", which actually served as a key comparative criterion for many debates preceding the relevant section in this volume and the conference panel before it. As the person who wrote that piece to prepare the conference panel in question I will quote the relevant text here to make the conceptualization accessible (with two minor alterations as indicated):

ENCLAVES OF LEARNING: In the social sciences and humanities, the concept of enclaves usually designates a sub-entity that is spatially, temporally, and by other socially defined means and borders separated from its wider environment, while simultaneously interacting with it out of that separation. By necessity, this goes together with three forms of coexisting and intersecting relations, namely, inside each enclave, among various enclaves of similar or related types, and as the main and defining form, between the enclave(s) and the outside world. Enclaves may have various purposes - some of them quite explicit and others more implicit, some of them of primary importance and others only in a secondary manner. One way of analytically distinguishing enclaves across different historical periods and various cultural realms is thus the identification of one or the other of their main purposes. 
As a concept, "enclaves of learning" therefore singles out one specific variety among enclaves, and one purpose among what may actually be a cluster of purposes. Military training camps or crafts' production centres may also be understood and investigated in their dimensions as enclaves of learning (and training). In the present context, however, enclaves of learning relates to some of those forms that were almost specific to certain regions and periods of medieval Europe and of Asia and the CircumMediterranean: this refers to such "enclaves of learning" that were to an important extent anchored in written texts and their transmission. In cultural contexts and at times when research and belief were intrinsically connected with each other, learning therefore refers as much to contents of faith and belief as to those of understanding and analysing.

Inside and among these entities, the research concept of "enclaves of learning" thus includes knowledge and its transfers and transmission forms about such texts: know-how about their location, access to them, how to read, translate, and interpret them, how to quote, copy and edit them, how to write new ones, and how to relate them to actual practices in ceremonial and discursive arenas as well as in everyday lives. Between these entities and their wider socio-cultural environments, "enclaves of learning" as a concept includes the recruitment of juniors, the question whether the two genders were thought to live and learn together or separately or if women were to be allowed to participate in specific forms of knowledge at all, the extent of popularizing textual knowledge, its reception among those who usually live outside these enclaves, the differences and inequalities in interpreting and applying the knowledge in question outside the enclaves (by orientation of opinion and by social access to the knowledge in question), and the forms of deviant knowledge that may emerge among the population outside these enclaves as much as, again, inside old or new enclaves.

[Within] the "Visions of Community" research project, "enclaves of learning" is embedding this concept inside the wider project concerns about "community": it thus relates to social and ideational processes of building, maintaining, and challenging communities inside and among these enclaves as well as between them and their wider socio-cultural environments. Main questions that could and should be addressed [here] therefore include, along a temporal axis: Under what conditions, and driven by which interests, did such enclaves first emerge in regional history (e.g. the Hijra enclaves in the Zaydi highlands of Southern Arabia after the 9th century)? Which were the circumstances allowing certain enclaves to succeed in becoming radiation centres for new ideas that 
took hold in their wider environments (e.g. Christian monasteries in central Europe during certain periods)? When and why did certain enclaves undermine the influence of earlier denominations and orientations, and with what kind of social messages and consequences (e.g. the rise of the Gelug-pa ['yellow hat'] version in Tibetan Buddhism during the late "Middle Ages", and the ensuing deterioration of nuns' and non-monastic women's position)? With regard to cognitive and intellectual specialization, what were the main institutional and personal competitors for enclaves of learning, within their respective historical and social environments, and cross-culturally?

Hovden and $\mathrm{Kramer}^{26}$ have elaborated the concept towards some of its more methodological and normative fields of application, while several of the other contributors to this volume acknowledge with or without reservations some heuristic value for present comparative purposes. From an author's perspective, the concept thus seems to have served its purpose fairly well. It has helped to highlight a specific socio-territorial concentration of intellectual expertise in stratified medieval agrarian societies of Eurasia, while opening up ample room for outlining internal diversities and typologies of all kinds. In this manner, the concept is an "abductive" tool of comparison as proposed in the second section of this chapter-searching for certain, theory-inspired parallels and commonalities that are grounded in available evidence.

On this basis, my second point leads on to the discussion of selected insights from this specific discussion on the basis of some of the case studies in the section. In this context, reference to insights from each of the three main religions seems appropriate-namely, Buddhism in medieval Tibet (Hugon), Islam in South West Arabia (Hovden), and Christianity in Central Europe (Lutter).

In another of this volume's studies on Tibeto-Buddhist visions of community, Pascale Hugon examines gSang phu as a specializing medieval enclave with an eminent foundational background, a network of intellectual and social influence, of dissemination, but also as a site to be addressed by incoming scholars. She outlines the philosophical turn promoted by the second abbot, and the possible consequences this had in Tibetan philosophical and Buddhist history. This also included affiliations to intellectual rather than spiritual communities, extending well beyond these specific monastic walls and also including "satellite" and other monasteries. In summing up, Hugon emphasizes that such an institutional, social, and intellectual setting promoted diversity in 
discourse, as well as movements beyond homogeneity and the mainstream. Even after gSang phu lost its initial prestige, the intellectual movements beyond their institutional point of emergence enabled ongoing processes to flourish elsewhere.

On the basis of three sources and periods, Hovden analyses differing forms of welfare practices and ideas in medieval Zaydi South Arabia between AD 900 and 1200. The first source shows how the first Zaydi Imam and descendant of the Prophet, al-Hadi, justified why and when the alms tax (zakat) would not have to be spent on the poor and others in need but for warfare. Two other examples then demonstrate how zakat and welfare could be conceptualized and used in non-Imamic-centred visions of community as promoted by the Mutarrifiya, a Zaydi movement of local Yemeni background. The first of these two cases shows how the zakat could be spent locally, while the second features how it was spent inside a hijra as an institutionalized enclave of learning whose forms and modes were contested at the time. Hovden aptly characterizes hijras as both the products of visions of communities, but also as frames in which such visions could be formulated, codified, and learned-for example for spending welfare. In doing this he further clarifies important differences between the Imam-centred and the Mutarrifi-based early hijras. Contrasting these sources with each other allows Hovden to situate them more precisely, and to distinguish visions of community on four levels: inside single enclaves on a face-to-face basis; within certain subsects as opposed to others; within the wider denomination (madhhab) inside Islam; and inside the wider regionally grounded Muslim community of believers.

Christina Lutter examines the Christian-monastic concept of "vita communis" and its relevance during the long period in which this specific way of life in medieval Europe enjoyed societal importance, and also in view of its entanglement with a variety of other social fields. Some key texts of medieval monasticism directly address community and vita communis, while also developing a related figurative vocabulary. These texts thereby refer to a specific way of life defined by regular practice as a primary instrument for adopting, training, and, hence, doing community. Moving beyond the limits of normative sources, the subsequent extension of consulted materials then modifies current modes of understanding these specific monastic communities and their relations to their outside worlds, also facilitating comparison with spiritual communities in Asia. Lutter thus demonstrates that at least in the European context, kinship, property, and gender cannot be separated from either the political or spiritual practices constitutive for these institutions, or from the visions of the people who made them into communities. These additional categories help to assess the different types of community to which a given monastery might 
belong; at the same time they provide an interface to eventually move beyond the European phenomenon of monastic houses with patterns of comparison for those parts of Eurasia in which monastery is not a useful term to address enclaves of spirituality and learning.

These insights by two of this volume's co-editors, and by a leading expert in Tibetan medieval studies, help us to return full circle to some of the main starting points from which these concluding remarks started: each of these three analyses begins by marking significant advances in its respective field of study, thereby first of all highlighting the specificities in each field and context. Beyond that, however, each also moves on to outline ranges of diversity within the region and its times, and how these ranges might relate to similar forms beyond the region and elsewhere in Eurasia.

In the end this leads on to a discussion, thirdly, of a few consequences of these analyses. Jonathan Lyon quite appropriately emphasizes that enclaves of learning of the more religiously oriented varieties of hijras and monasteries may also be seen in their interrelation with other, more academic forms of learning such as the prototypes of medieval universities. He also emphasizes that at most levels of comparison, what was learned in many of those enclaves of learning differed quite significantly between (but also, I would like to add, within) these various religious traditions-so, as also is suggested by Vanderputten (this volume), perhaps how learning proliferated gradually became as important as what the learning was all about.

These reflections are helpful, and I share their general orientation. The most engaged "pro axial age" participants in their own debates of course have tended to adopt different positions by emphasizing commonalities of rationales, and hence of content and inner logic, across axial age religions and philosophies. One may well sustain the argument that elements of public moralizing and of self-discipline remained common to all of those world religions while they proliferated. However, those commonalities became less and less visible with the proliferation and dissemination into increasingly diverse theological and epistemological orientations, while, simultaneously, distinctions between monotheism and polytheism were not systematically attenuated.

Yet while those diversities of content expanded into ever-widening richness, diversity, and multiplicity, the social and institutional foundations and techniques of learning indeed maintained and strengthened certain elements displaying greater similarity across medieval and early modern Eurasia. First of all, writing and reading were gradually leaving behind their status as secret elite techniques wherever this was made accessible to a gradually growing cohort from other strata and status groups-be that through their access to regular trade or formal administration, at court or, precisely, in religious 
hierarchies. Second, wherever these opportunities were passed down over generations, they promoted standardization in communication, an element of reliability within interactions that were not primarily based on face-to-face communication, and the storage and transmittance of ideas and knowledge $^{27}$ - together with the downside of these same processes, namely, the potential to facilitate contrasts among orthodoxy, dogma, and heresy.

Nevertheless, within these multifaceted, uneven, and dispersed processes, and after scriptural communication had been established among many Eurasian elites, medieval "enclaves of learning" represented the possibility for crucial institutional turning points. They helped to create critical mass in the sense that mathematicians and physicists use the term: decisive nuclear points emerged in which the arts of writing and reading became not something special, but rather perfectly normal forms of expressing values, beliefs, insights, convictions, arguments, messages, orientations, and visions. Once enclaves of learning had been established and continued to exist across generations, the understanding that knowledge and insights were techniques and processes to be acquired and achieved, and not only inherited among special upper status groups grew and spread beyond their walls. The possible relations between the enclaves of learning as discussed here - that is, with a still inherent more formal religious hegemony - and those proto-universities of a somewhat more pragmatic and secular orientation - as they had already emerged in urban settings of southern Europe, China, and the Middle East during the first medieval centuries-still needs some careful further exploration and investigation. Even if enclaves of learning had no direct impact on proto-universities, through their institutionalized relevance they nevertheless broadened the social and cognitive basis for access to active and passive written expertise. After all, enclaves of learning are a good indicator of the undeniable fact that during the higher and later medieval centuries, Eurasia was gradually moving toward a new historical threshold phase in the social and technological organization of scriptural cultures.

That movement progressed through the gradual proliferation of writing and copying as a manual craft—and at least in part through the establishment and proliferation of institutionalized enclaves of learning, these processes eventually approached the watershed phase when, to paraphrase Walter Benjamin, ${ }^{28}$ the arts and crafts of writing and reading gradually entered their very specific "age of technical reproduction".

27 Gellner, Plough, Sword and Book; Goody, Logic of Writing.

28 Benjamin, "The Work of Art". 
Based on Tibetan practices of using wooden printing blocks and on the Han craftsman Bi Sheng's pioneering invention, the first metal movable-type system for printing was developed by Chinese and Korean experts between the 11th and the 13th centuries. Something that operated in very similar ways was independently invented by Johannes Gutenberg around 1450. These media revolutions contributed to the dawn of a new era in the multiple trajectories of world history.

\section{Bibliography}

Karen Armstrong, The Great Transformation: The Beginning of Our Religious Traditions (New York, 2006).

Jóhann P. Árnason, "The Axial Age and its Interpreters: Re-opening a Debate", in Axial Civilization and World History, eds. Johann P. Árnason, Shmuel N. Eisenstadt and Björn Wittrock (Leiden, 2005), 19-49.

Nicolas Baumard, Alexandre Hyafil, Ian Morris and Pascal Boyer, "Increased Affluence Explains the Emergence of Ascetic Wisdoms and Moralizing Religions", Current Biology 25 (2015), 10-15.

Walter Benjamin, "The Work of Art in the Age of Technical Reproduction", in Illuminations: Essays and Reflections, ed. Hannah Arendt and trans. Harry Zohn (French orig. 1936; Germ. orig. 1955; New York, 1968), 217-52.

Hinnerk Bruhns and Wilfried Nippel, eds., Max Weber und die Stadt im Kulturvergleich, Kritische Studien zur Geschichtswissenschaft 140 (Göttingen, 200o).

Dipesh Chakrabarty, Provincializing Europe: Postcolonial Thought and Historical Difference (Princeton, NJ, 2000).

Walter Dostal, “Zur Frage der Konstanz von Kulturformen”, in Festschrift für Adolf E. Jensen, Teil 1, eds. Eike Haberland, Meinhard Schuster and Helmut Straube (Munich, 1964), 91-101.

Shmuel N. Eisenstadt, ed., The Origins and Diversity of Axial Age Civilizations (Albany, NY, 1986).

Edward E. Evans-Pritchard, The Nuer: A Description of the Modes of Livelihood and Political Institutions of a Nilotic People (Oxford, 1940).

Roland Fletcher, The Limits of Settlement Growth: A Theoretical Outline (Cambridge, 2007).

Roland Fletcher, "Low-Density, Agrarian-Based Urbanism: Scale, Power, and Ecology", in The Comparative Archaeology of Complex Societies, ed. Michael E. Smith (New York, 2012), 285-320.

Ernest Gellner, Plough, Sword and Book: The Structure of Human History (Chicago, 1988). 
Andre Gingrich, "Comparative Methods in Socio-cultural Anthropology Today", in The SAGE Handbook of Social Anthropology, vol. 2, eds. Richard Fardon, Olivia Harris, Trevor H.J. Marchand, Mark Nutall, Cris Shore, Veronica Strang and Richard A. Wilson (Los Angeles, 2012), 201-14.

Andre Gingrich, "Multiple Histories: Three Journeys through Academic Records, Medieval Yemen, and Current Anthropology's Encounters with the Past", History and Anthropology 26 (2015), 110-28.

Andre Gingrich and Christina Lutter, "Visions of Community: An Introduction", History and Anthropology 26 (2015), 1-7.

Jack Goody, The Logic of Writing and the Organization of Society (Cambridge, 1986).

David Graeber, Debt: The First 5000 Years (Brooklyn, 2011).

Lawrence Grossberg, "Identity and Cultural Studies: Is That All There Is?" in Questions of Cultural Identity, eds. Stuart Hall and Paul du Gay (London, 1996), 87-107.

Chris Hann, "Towards a Maximally Inclusive Concept of Eurasia", Max Planck Institute for Social Anthropology Working Papers 157 (Halle/Saale, 2014).

Eirik Hovden and Rutger Kramer, "Wondering about Comparison: Enclaves of Learning in Medieval Europe and South Arabia-Prolegomena to an Intercultural Research Project", Networks and Neighbours 2 (2014), 20-45.

Karl Jaspers, The Origin and Goal of History (Germ. orig. 1949; New York, 2011).

Edmund Leach, Rethinking Anthropology (London, 1961).

Christina Lutter, "Comparative Approaches to Visions of Community", History and Anthropology 26 (2015), 129-43.

Alois Musil, The Manners and Customs of the Rwala Bedouins (New York, 1928).

Joseph Needham, The Shorter Science and Civilisation in China: An Abridgement of Joseph Needham's Original Text, 7th ed. (1980; Cambridge, 1997).

Monika Palmberger and Andre Gingrich, "Qualitative Comparative Practices: Dimensions, Cases, and Strategies", in The SAGE Handbook of Qualitative Data Analysis, ed. Uwe Flick (Los Angeles, 2014), 94-108.

Robert Parkin, Kinship: An Introduction to Basic Concepts (Oxford, 1997).

Talcott Parsons, Action Theory and the Human Condition (New York, 1978).

Walter Pohl, "Comparing Communities: The Limits of Typology", History and Anthropology 26 (2015), 18-35.

Karl Polanyi, Conrad M. Arensberg and Harry W. Pearson, eds., Trade and Markets in the Early Empires (Glenco, 1957).

Jo Reichertz, "Abduction, Deduction and Induction in Qualitative Research", in $A$ Companion to Qualitative Research, eds. Uwe Flick, Ernst von Kardorff and Ines Steinke (London, 2004), 159-65.

Barbara H. Rosenwein, "An Historian in the Amazon", History and Anthropology 26 (2015), 76-79. 
Jörg Rüpke, Religion in Republican Rome: Rationalization and Ritual Change (Philadelphia, PA., 2012).

Andrew Shryock, Nationalism and the Genealogical Imagination: Oral History and Textual Authority in Tribal Jordan (Oakland, CA, 1997).

Ferdinand Tönnies, Community \& Society (Germ. orig. 1887; East Lansing, MI, 1957).

Max Weber, Wirtschaft und Gesellschaft: die Wirtschaft und die gesellschaftlichen Ordnungen und Mächte Teilband 5: Die Stadt, ed. Wilfried Nippel, Max Weber, complete edition, vol. I/22-5 (Germ. orig. 1921/22; Tübingen, 1999). 